\title{
TRADUÇÃO \\ Reconhecibilidade, percepção e a partilha do sensível: Honneth, Rancière e Butler ${ }^{1}$
}

Danielle Petherbridge ${ }^{2}$

Resumo: Este artigo explora a relação entre percepção e reconhecibilidade nos trabalhos de Honneth, Rancière e Butler. 0 termo reconhecibilidade é utilizado para indicar o processo perceptivo que necessariamente antecede um ato normativo ou ético de reconhecimento e que fornece as condições que tornam o reconhecimento possível. A noção de reconhecibilidade aponta o fato de que a percepção não corresponde a uma mera observação desinteressada do campo perceptivo e indica que tal apreensão já é valorativa, uma vez que outras pessoas são imediatamente distinguíveis de outros objetos. Quando a reconhecibilidade fracassa, não é porque a outra pessoa não foi vista no sentido literal, mas sim porque ela foi intencionalmente ignorada ou invisibilizada. A sugestão que faço aqui é a de que, embora possuam abordagens distintas, uma comparação e um diálogo entre esses três pensadores explicita a importância dessa constelação de questões para a teoria crítica.

Palavras-chave: Honneth, Rancière, Butler, percepção, invisibilidade, reconhecibilidade.

A noção de reconhecimento tornou-se central na teoria crítica contemporânea como uma forma de examinar as pretensões normativas ou éticas que são, para alguns, intrínsecas à nossa sociabilidade. Embora o reconhecimento tenha sido minuciosamente examinado nos trabalhos de teóricos críticos como Axel Honneth e Judith Butler, a relação entre reconhecimento, percepção e o problema da reconhecibilidade ${ }^{3}$ não é tão clara. Eu sugiro que a questão da reconhecibilidade, que é anterior às bases sobre as quais outras afirmações normativas são articuladas, é um aspecto central, mas que recebeu pouca atenção nos trabalhos sobre reconhecimento. Nesse sentido, os fenômenos da perceptibilidade, da reconhecibilidade e da visibilidade, ou daquilo que permite que alguém seja reconhecível, são fundamentais para essa discussão.

1 Tradução de "Recognizability, Perception and the Distribution of the Sensible: Honneth, Rancière and Butler". Uma primeira versão deste artigo foi publicada em inglês no Journal of French and Francophone Philosophy, 27(2), 2019, 54-75 DOI: https://doi.org/10.5195/jffp.2019.894. Tradução de Amanda Soares de Melo, Gabriel Valim Alcoba Ruiz, Kadú Firmino, Michele Teixeira Bonote, Nathalie Bressiani.

2 School of Philosophy, University College Dublin, Irlanda.

3 Optou-se traduzir o termo recognizability por reconhecibilidade, recognition por reconhecimento e acknowledgment por tomada de conhecimento (N.T.). 
Neste artigo, discuto o trabalho de três teóricos críticos contemporâneos que se concentram no que chamo de problema da reconhecibilidade. Axel Honneth, Judith Butler e Jacques Rancière abordam algo que, em linhas gerais, poderíamos chamar de processos ou estruturas que possibilitam ou bloqueiam o reconhecimento e que, em casos de bloqueio, geram formas de invisibilização. Embora Honneth, Butler e Rancière talvez não concordem com os termos da abordagem aqui proposta, nem mesmo no modo de interrogar a invisibilidade, uma comparação e um diálogo entre suas respectivas abordagens mostra a centralidade do problema da reconhecibilidade.

A noção de reconhecibilidade empregada aqui é conceitualizada em relação à percepção. ${ }^{4}$ Essa noção aponta o fato de que a percepção não é uma observação desinteressada do campo visual, mas algo que indica que outros seres humanos nesse campo são imediatamente distinguíveis de outros objetos. 0 momento da percepção não é um ato normativo ou ético enquanto tal; porém, antes que atos normativos mais explícitos de reconhecimento sejam possíveis, é preciso tomar conhecimento do outro como um ser igual a si próprio. Reconhecibilidade é o termo que emprego para indicar o processo perceptivo que necessariamente ocorre antes de um ato explicitamente normativo ou ético de reconhecimento. A noção de reconhecibilidade aponta, nesse sentido, as condições que tornam o reconhecimento possível; essa noção é, portanto, central para o sucesso ou para o fracasso das relações normativas de reconhecimento. 0 argumento aqui é o de que relações mútuas e normativas de reconhecimento dizem respeito a um processo secundário que ocorre após um ato inicial de tomada de conhecimento [acknowledgment] no qual o outro se torna reconhecível, e, além disso, que esse ato é a base de qualquer concepção de reconhecimento

É importante notar, porém, que não há garantia de que seremos considerados reconhecíveis. Quando há um fracasso na percepção, isso não decorre do fato de o outro não ter sido visto em sentido literal, e sim, segundo Honneth, porque ele ou ela foi ativa ou intencionalmente ignorado ou invisibilizado. Para dar um exemplo: o problema da reconhecibilidade é retratado de modo evocativo por Toni Morrison em $O$ olho mais azul, ${ }^{5}$ quando ela escreve sobre o fracasso da reconhecibilidade em relação a uma jovem negra que visita um pequeno armazém em Ohio, no Centro-Oeste dos Estados Unidos. Assim que a garota entra no estabelecimento, o lojista branco ergue os olhos de trás do balcão e, rapidamente, "arranca os olhos dos próprios pensamentos para fitá-la" (Morrison, 2019, p. 51-52 [2007, p.48]). Entretanto, no momento da percepção, "em algum ponto entre a retina e o objeto, entre a visão

4 A noção de percepção deve ser entendida de forma ampla, incluindo não apenas a visão, mas também todo o espectro de responsividade afetiva e sensível, incluindo a audição e o tato.

5 Sempre que possível, seguimos as traduções brasileiras, cujas paginações foram indicadas, acompanhadas pelas referências originais entre colchetes. Quando necessário, fizemos alterações na tradução para garantir a padronização dos termos centrais (N.T.). 
e a vista, seus olhos recuam, hesitam, pairam" (idem, ibidem). Como Morrison escreve: "Em algum ponto fixo no tempo e no espaço, ele [o lojista] sente que não precisa desperdiçar o esforço de um olhar. Não a vê, porque, para ele, não há nada a ser visto" (idem, ibidem, trad. mod.). Como se pode esperar que ele "veja uma menina negra? Nada em sua vida nunca sequer sugeriu que a proeza fosse possível, que dirá desejável ou necessária" (idem, ibidem, trad. mod.). ${ }^{6}$ Nesse caso, Morrison evoca uma sensação de total ausência de reconhecimento para indicar que um ato perceptivo primário de reconhecibilidade não ocorreu.

Caso tomasse essa cena como exemplo, Butler procuraria explicar a ausência de apreensão como resultado de um problema epistemológico, uma vez que a reconhecibilidade do outro é determinada por estruturas epistemológicas que, antes de tudo, estabelecem o que é reconhecível. Onde a reconhecibilidade não ocorre, Butler chama a atenção para os quadros epistemológicos que constroem formas de conhecimento e, portanto, moldam a percepção; nesse caso, percepção em relação às formas de racialização. Em contrapartida, Honneth explicaria esse fracasso perceptivo como um ato deliberado ou intencional de invisibilização que resulta de relações sociais patológicas que culminam em formas de reificação ou objetivação. A explicação de Honneth, portanto, baseia-se diretamente em uma afirmação antropológica de acordo com a qual as relações de reconhecimento são primárias e todos os fracassos de reconhecimento representam um esquecimento das relações sociais originárias. Por fim, Rancière talvez descrevesse o problema da invisibilização e o fracasso da reconhecibilidade, retratados no texto de Morrison, como o resultado de uma construção particular do campo sensível, no sentido de que o campo do sensível é moldado por uma ordem político-estética particular que determina quem é reconhecível ou visível em qualquer momento.

Partindo desse exemplo, o problema dual examinado neste artigo é o seguinte: (1) a primazia e a importância da reconhecibilidade como aquilo que fornece as condições de possibilidade das relações normativas de reconhecimento; (2) um exame sobre o que bloqueia ou impede a reconhecibilidade e sobre a melhor maneira de explicar tais fracassos.

Para explorar esse conjunto de questões, o artigo começa com uma discussão sobre o reenquadramento e a articulação que Butler faz das distinções entre reconhecimento, inteligibilidade e apreensão, ou aquilo a que ela se refere como reconhecibilidade. Na segunda parte do artigo, contrasto a maneira como Honneth concebe a relação entre reconhecimento, percepção e cognição, à sua interpretação da invisibilização como um esquecimento das relações primárias de intersubjetividade. $\mathrm{Na}$ seção final do artigo, considero a abordagem específica de Rancière sobre

6 Ver ainda minha descrição em Patherbridge (2017), onde também recorro ao texto de Morrison em virtude de sua imensa relevância para esse conjunto de assuntos. 
reconhecibilidade e invisibilidade de acordo com a organização particular do social, e examino sua compreensão da política como um meio de perturbar as estruturas de invisibilização. Discuto, na conclusão, de que modo um diálogo entre esses três pensadores esclarece e problematiza, mas, também, enriquece essa constelação de questões e defendo a importância do problema da reconhecibilidade para a teoria crítica.

\section{Reformulando a reconhecibilidade com Butler: Tornando o outro vulnerável inteligível}

Não é de hoje que a noção de reconhecimento figura na obra de Butler de diferentes modos, da formulação althusseriana do reconhecimento como interpelação, em $A$ vida psíquica do poder, a uma descrição mais explicitamente ética do reconhecimento em relação à vulnerabilidade em trabalhos posteriores, como Vida precária, Quadros de guerra e Corpos em aliança e a política das ruas. Neste último trabalho, Butler identifica o problema dual do reconhecimento e da reconhecibilidade quando escreve:

A questão do reconhecimento é importante porque, se acreditamos que todos os sujeitos humanos merecem igual reconhecimento, presumimos que todos os sujeitos humanos são igualmente reconhecíveis. Mas, e se o campo altamente regulado da aparência não admitisse todo mundo, exigindo zonas em que se espera que muitos não apareçam (...)? Por que esse campo é regulado de tal modo que apenas determinados tipos de seres podem aparecer como sujeitos reconhecíveis, e outros não podem? (Butler, 2019a, p. 42 [2015, p. 35]).

Butler aponta aqui o problema da (in)determinidade daqueles que são visíveis no espaço de aparências, mas ela já havia identificado o problema da reconhecibilidade em sua discussão sobre a inter-relação entre vulnerabilidade, reconhecimento e responsividade ética para com os outros em Vida precária. Em uma passagem central, Butler assevera:

A vulnerabilidade deve ser percebida e reconhecida para entrar em jogo no campo ético, e não há nenhuma garantia de que isso vá acontecer. Existe sempre a possibilidade de que a vulnerabilidade não seja reconhecida e de que seja constituída como "irreconhecível", mas também a de que, quando a vulnerabilidade é reconhecida, esse reconhecimento tenha o poder de alterar o significado e a estrutura da própria vulnerabilidade (Butler 2019b, p. 45 [2004, p. 43], trad. mod.).

Aqui, a questão da reconhecibilidade é concebida por Butler sob a lente da vulnerabilidade como base para uma ética ou para aquilo que, em trabalhos posteriores, ela descreveu como precariedade ou exposição ao outro. Nesse contexto, ela sugere que o outro tem de ser primeiro identificado como uma vida, uma vida 
que é passível de luto, para que o outro vulnerável seja reconhecido (2019b, p. 39 [2004, p. 20]; Ferrarese, 2011, pp. 759-73). Assim, Butler argumenta que, embora seja uma condição universal, no sentido de uma "pré-condição para a humanização", a vulnerabilidade também é "fundamentalmente dependente das normas existentes de reconhecimento", que são condicionadas pelo poder (idem, p. 58 [p. 43]). Para Butler, diferentemente de Honneth, vulnerabilidade e reconhecimento são sempre conceituados em relação ao poder (idem, p. 60 [p. 45]). Desse modo, embora Butler teorize o reconhecimento como aquilo que nos leva para além de nós mesmos, sua concepção althusseriana de sujeito, anteriormente delineada em $A$ vida psíquica do poder, continua a informar seu trabalho. Nessa formulação, o reconhecimento é construído em relação ao modelo de formação do sujeito como sujeição e, desse modo, sempre tem duas faces. É simultaneamente dominador e possibilitador. Com isso, Butler descreve o sujeito do reconhecimento como "entregue a um conjunto de normas culturais e a um campo de poder que nos condicionam fundamentalmente" (idem, p. 60 [p. 45]; Mills 2007, pp. 133-56).

Em Quadros de guerra, todavia, Butler formula distinções mais nuançadas e, de modo profícuo, identifica as diferenças entre reconhecimento e reconhecibilidade, além de sublinhar o problema relativo ao campo ou terreno no qual a reconhecibilidade pode ou não ocorrer. Para Butler, a reconhecibilidade é anterior ao reconhecimento, assim, dando um passo a mais, ela também argumenta que as condições de reconhecibilidade são estruturadas pelo que denomina quadros de inteligibilidade. Nesse esquema, Butler destaca as normas que primeiro determinam a reconhecibilidade e os quadros de inteligibilidade que produzem essas normas e determinam o que é conhecível ou inteligível. Em sua concepção de vulnerabilidade ou precariedade, portanto, a autora efetivamente identifica o processo e as estruturas de invisibilização. A esse respeito, a diferenciação feita por Butler entre reconhecibilidade e reconhecimento parece ter alguns elementos em comum com a interpretação de Honneth; porém, como veremos adiante, as diferenças entre eles são também instrutivas.

Em Vida precária, Butler dá mais credibilidade a uma base ontológica para a ética e indica uma conexão mais uniforme entre nossa condição humana compartilhada de vulnerabilidade e nossas obrigações éticas baseadas em uma teoria do reconhecimento. Em Quadros de guerra, no entanto, ela parece recuar da pretensão mais forte de ancorar uma ética na condição ontológica da vulnerabilidade. Em vez disso, Butler parte de uma abordagem baseada em quadros de normalização que precederiam a tomada de conhecimento e o reconhecimento. Nesse esquema alterado, nos seus termos, é preciso ser capaz de apreender o outro como uma vida antes que ele ou ela possa ser reconhecido, mas essa apreensão depende de quadros de inteligibilidade que estruturam o que pode ser conhecido como um todo (Butler 
2015, p.12 [2010, p.6]; Patherbridge, 2018).

Em Quadros de guerra, ela também faz uma distinção entre precariedade, como uma categoria ontológica ou "uma condição generalizada dos seres vivos", e condição precária, como uma categoria social e política que diz respeito ao modo como as formas de precariedade são diferentemente distribuídas ou alocadas. Além disso, ela argumenta que nossa capacidade de responsividade ética "depende dos enquadramentos por meio dos quais o mundo é dado" (idem, p. 251 [p. 180]). Como consequência, ela também rejeita a sensibilidade levinasiana, evidente em Vida precária, segundo a qual a reivindicação ética de um outro vulnerável pode ser feita mesmo sem que tenha sido prescrita por estruturas formais de conhecimento e, portanto, sem depender do "problema epistemológico de apreender uma vida" (idem, p. 12 [p. 3]). No contexto de Quadros de guerra, entretanto, seu argumento é o seguinte: "Se certas vidas não se qualificam como vidas (...) no interior de certos enquadramentos epistemológicos, então essas vidas nunca serão" concebíveis como violáveis ou vulneráveis (idem, p. 12 [p. 2]). Uma vida não pode ser considerada como passível de luto ou como perdida se, primeiro, não for apreendida como um outro ser vivo.

Nesse sentido, Butler parece sugerir que determinados quadros de conhecimento precedem a tomada de conhecimento do sofrimento do outro. Ela escreve:

A capacidade epistemológica de apreender uma vida é parcialmente dependente de que essa vida seja produzida de acordo com normas que a caracterizam como uma vida ou, melhor dizendo, como parte da vida. Desse modo, a produção normativa da ontologia cria o problema epistemológico de apreender uma vida, o que, por sua vez, dá origem ao problema ético de definir o que é tomar conhecimento (idem, p. 15 [p. 3]).

Em muitos aspectos, como veremos adiante, Butler parece sugerir que o reconhecimento é uma categoria de segunda ou mesmo de terceira ordem. Para melhor entender seu argumento temos de examinar sucintamente outros termos importantes de sua teoria.

É significativo que Butler argumente pela necessidade de distinguir entre os termos reconhecimento, inteligibilidade e apreensão (ou aquilo que ela também denomina reconhecibilidade). Como ela escreve, a apreensão diz respeito a uma forma de "marcar, registrar ou tomar conhecimento sem uma cognição plena. Tratase de uma forma de conhecimento que está associada ao sentir e ao perceber, mas de maneiras que não são sempre - ou não são ainda - formas conceituais de conhecimento" (idem, p. 17 [p. 5], trad. mod.). Butler diferencia a noção de apreensão ou reconhecibilidade daquilo que ela descreve como uma noção hegeliana de reconhecimento. Para ela, reconhecimento diz respeito a "um ato ou prática" realizado por pelo menos dois sujeitos e que "depende de normas que facilitam o 
reconhecimento" (idem, p. 17 [pp. 4-5]). Aapreensão de alguém, porém, não é limitada pelas normas existentes de reconhecimento; Butler argumenta que a apreensão pode ser facilitada por tais normas, mas que não é por elas circunscrita. A esse respeito, ela sugere que é necessário distinguir entre reconhecimento e reconhecibilidade. Nesse sentido, para Butler, enquanto "o reconhecimento caracteriza um ato, uma prática ou mesmo uma cena entre sujeitos" (idem, p. 18 [p. 5]), “a reconhecibilidade caracteriza as condições mais gerais que preparam ou moldam um sujeito para o reconhecimento [isto é] - os termos gerais, as convenções e as normas (...) [que tornam] um ser vivo em um sujeito reconhecível" (idem, p. 18 [p. 6]) e permitem que o reconhecimento ocorra. Como consequência, para Butler, a reconhecibilidade necessariamente precede o reconhecimento (idem, p. 18 [p. 5]).

A questão a respeito do que torna alguém reconhecível é, no entanto, determinada pelas estruturas primárias ou quadros de inteligibilidade que condicionam qualquer ato de reconhecibilidade. Nesse sentido, o processo de reconhecibilidade está situado entre quadros de inteligibilidade e atos normativos de reconhecimento. Butler afirma, então, que uma vida tem de ser conhecível antes de ser reconhecível. Em suas palavras,

uma vida tem que ser inteligível enquanto uma vida, tem de se conformar a certas concepções do que é a vida, a fim de se tornar reconhecível. Assim, da mesma forma que as normas da reconhecibilidade preparam o caminho para o reconhecimento, os esquemas de inteligibilidade condicionam e produzem essas normas (idem, p. 20 [p. 7]).

Para Butler, portanto, os quadros de inteligibilidade estruturam o campo do que é conhecível e, com isso, determinam ocampo sensível eperceptivo da reconhecibilidade. O foco de Butler nos quadros de inteligibilidade e na primazia do conhecível parece sugerir que reconhecibilidade e reconhecimento são categorias de segunda e terceira ordem, respectivamente. Desse modo, os quadros de inteligibilidade são o campo subjacente que possibilita ou impede a reconhecibilidade. As relações normativas de reconhecimento só se tornam possíveis em um terceiro passo, depois que a pessoa foi tornada reconhecível.

Butler explica que os quadros organizam e delimitam a experiência visual e determinam o que pode ser apreendido e quais objetos em nosso campo perceptivo são reconhecíveis como outras vidas humanas. No entanto, ela também tem a cautela de afirmar que as normas que estruturam o campo visual persistem apenas mediante sua reiteração, e, portanto, que essas normas se alteram em um processo contínuo de renovação. Desse modo, os quadros de inteligibilidade requerem determinadas condições de "reprodutibilidade para terem êxito" (idem, p. 24 [p.10]). No processo de perpétua renovação, esses quadros estão sujeitos à "reversão" ou à "subversão" e estão, portanto, abertos a um "risco estrutural" que pode causar uma ruptura 
ou quebra no local da reprodução (idem, p. 39 [p. 24]). ${ }^{7}$ Nesse contexto, Butler também sugere que uma vida pode "exceder as condições normativas de sua reconhecibilidade" (idem, p. 17 [p.4]). No entanto, em Quadros de guerra, ela deixa claro que a reconhecibilidade é mais importante que o reconhecimento, não apenas porque a reconhecibilidade determina se o reconhecimento ocorrerá, mas também porque, a seu ver, "simplesmente não temos como recorrer a normas de reconhecimento singulares e separadas", pois, ela continua, somos posicionados por “condições mais gerais de 'reconhecibilidade', que são historicamente articuladas e implementadas" (idem, pp. 16-17; [p. 5]).

À primeira vista, e antes da introdução da noção de quadros de inteligibilidade, a diferenciação oferecida por Butler entre reconhecibilidade e reconhecimento parece ter alguns elementos em comum com a concepção de reconhecimento em dois níveis elaborada por Honneth, como discutiremos adiante. Em alguns momentos, Butler se refere a um tipo de "responsividade afetiva primária" (idem, p. 57 [p. 34]) frente à vulnerabilidade ou à precariedade, e, com isso, ela localiza a responsividade no domínio afetivo. Do mesmo modo, sua tentativa de designar uma forma para a reconhecibilidade que antecede uma concepção completa do reconhecimento, enquanto ato normativo recíproco, parece ter algumas afinidades com as distinções elaboradas por Honneth. Há, porém, algumas diferenças significativas entre suas abordagens. Como discutiremos na seção seguinte, Honneth parte de uma posição intersubjetivista forte, que postula uma forma originária de intersubjetividade ou relacionalidade afetiva, e defende que formas de invisibilização (ou reificação) podem ser entendidas como uma perda temporária, um encobrimento ou esquecimento de uma forma elementar de reconhecimento. Em contraposição, em vez de considerar uma noção de intersubjetividade primária, Butler parte de uma concepção de quadros de inteligibilidade ou de quadros de normalização que estruturam o que é conhecível ou reconhecível. Nesse sentido, Honneth e Butler possuem pontos de partida significativamente distintos, e isso molda como cada teórico conceitualiza a questão da reconhecibilidade.

É também digno de nota que a maneira como Butler concebe as diferenciações entre reconhecibilidade, reconhecimento e os quadros que determinam o que é conhecível, ressoa com um conjunto de problemas também identificado por Rancière. A tentativa de Butler de elaborar sobre os problemas da invisibilização e da reconhecibilidade por meio da noção de quadros epistemológicos ou discursivos do conhecimento opera em paralelo à noção de ordem institucional que Rancière associa à polícia e que circunscreve o que e quem é visível, dizível e pensável.

7 Em Quadros de guerra, Butler defende que seu conceito de quadros de inteligibilidade "não aceita uma explicação estruturalista da norma", antes, esse conceito afirma "alguma coisa sobre o contínuo da vida no pós-estruturalismo" (idem, p. 257 [p. 169]). 
Porém, enquanto Butler continua sendo influenciada por sua herança estruturalista e articula essa abordagem em termos de quadros de inteligibilidade, Rancière reúne uma concepção de estética e de política em sua noção de partilha do sensível, por ele definida como a relação "entre uma forma de experiência sensorial e uma interpretação que dê sentido a ela” (Rancière, 2016a, pp. 133-155. Trad. nossa). Como ele sugere, trata-se de "uma matriz que define toda a organização do que visível, do que é dizível e do que é pensável” (idem, p. 136). Há, não obstante, pontos consideráveis de sobreposição entre os projetos de ambos, sobretudo a tentativa de pensar o problema do que determina o que pode ser visto, dito e conhecido. Adiante, trataremos de modo mais detido a abordagem de Rancière, incluindo sua combinação entre política e estética. Antes, contudo, voltemo-nos à concepção honnethiana de reconhecibilidade como uma forma primária de responsividade afetiva ao outro.

\section{Antes do reconhecimento: reconhecibilidade como engajamento afetivo e atento em Honneth}

Embora em seu trabalho mais recente Honneth ressalte os aspectos históricos e institucionais do reconhecimento e desenvolva uma concepção mais explícita de liberdade, em ensaios anteriores, de 2001 e 2008, ele mostra como formas de reconhecimento moldadas histórica e institucionalmente resultam de uma postura mais originária ou primária de reconhecimento (Honneth, 2008; 2001, pp. 127-139). ${ }^{8}$ Nesse sentido, Honneth desenvolveu o que os comentadores denominaram concepção de reconhecimento em dois níveis, distinguindo entre uma forma elementar de reconhecimento e aquelas formas de reconhecimento mais normativamente substantivas que são, segundo ele, condições intersubjetivas básicas necessárias a uma formação subjetiva bem-sucedida (Varga, 2010, pp.19-33).

De acordo com Honneth, embora seja a precursora de todas as formas explicitamente normativas de reconhecimento, a forma primária de reconhecimento não é determinada por normas derivadas ou estabelecidas institucionalmente. Antes, essa forma subjacente de reconhecimento representa uma forma não epistêmica de reconhecimento e é caracterizada pela postura "que assumimos diante do outro, uma postura bastante afetiva na medida em que podemos reconhecer nele o outro de nós mesmos, nosso próximo" (Honneth, 2018, p. 202 [2008, p. 151]). A forma de reconhecimento primário a que Honneth se refere indica uma postura emocional e afetiva, e não uma postura epistêmica, perante os outros e o mundo (idem, p. 118 [p. 90]). Em comparação com a maneira como Rancière concebe a partilha do sensível e demanda por uma igualdade originária, ou com a concepção de Butler de quadros epistemológicos que estruturam o domínio do que pode ser conhecido, para

$8 \mathrm{Em}$ trabalhos mais recentes, Honneth se voltou para uma descrição institucional (2015 [2015]). 
explicar por que algumas vidas (para usar o termo de Butler) são ou não reconhecíveis, Honneth recorre a uma concepção baseada no esquecimento de relações originárias de reconhecimento que é causado por patologias sociais.

Já em seu ensaio de 1982, "Consciência Moral e Dominação de Classe", Honneth escreveu sobre o problema da invisibilização ou sobre o que chamou de exclusão cultural das classes sociais oprimidas. Nesse contexto, ele sublinhou em particular o silenciamento de formas de conflito moral ou de sentimentos sociais de injustiça que, a seu ver, "estão por detrás da fachada de integração do capitalismo tardio” (Honneth, 1995, pp. 205-219; 207. Trad. nossa). Ali, sua crítica também estava direcionada ao modelo habermasiano de sociedade e de esfera pública, 0 qual levou à exclusão de certas vozes e formas de protesto moral do campo de conflito de classes capitalista; em outras palavras, aquelas formas de injustiça que não se transformam em modos formais de articulação pública e não se tornam reivindicações morais plenamente elaboradas (idem, p. 207; 209). Neste primeiro ensaio, Honneth parece próximo de Rancière quando argumenta que: "Essas técnicas de controle representam estratégias para a manutenção da hegemonia cultural da classe socialmente dominante ao estreitar de modo latente as possibilidades de articulação das experiências de injustiça” (idem, pp. 212-213). A esse respeito, Honneth critica sobretudo o modo como essas formas de exclusão estão baseadas na privação de "meios linguísticos e simbólicos", invisibilizando a parcela dos semparcela, para usar os termos de Rancière (idem, p. 213).

A concepção de Honneth sobre invisibilidade e o problema da reconhecibilidade são mais bem articulados em sua concepção mais recente de reconhecimento, na qual ele examina a inter-relação entre percepção e reconhecimento. No contexto de seu ensaio «Invisibilidade», Honneth examina essa constelação de questões ao se referir ao romance $O$ homem invisível, de Ralph Ellison, e a suas vigorosas descrições da invisibilização em interações cotidianas. Nesse contexto, Honneth faz uma distinção entre o sentido literal e o sentido figurado de invisibilidade, de acordo com a qual a invisibilidade do protagonista de Ellison não pode ser entendida como uma nãopresença física, mas se refere à invisibilidade nos termos de uma negação de sua existência social (Honneth, 2001, pp. 127-139; p. 111. Trad. nossa). Como sugere Honneth, um dos exemplos mais proeminentes desse tipo de invisibilização é o modo pelo qual "a nobreza [na Europa] podia se despir na frente de seus servos porque, em certo sentido, estes não estavam presentes"; práticas que também ocorreram na América nas atitudes e no tratamento em relação aos escravos. Quanto a isso, Honneth afirma que essas formas de invisibilização são uma expressão do domínio daqueles que estão em posições sociais de poder, de modo que a percepção se torna uma ferramenta de dominação (idem, p. 112).

Além disso, Honneth argumenta que podemos diferenciar o grau de dano 
infligido nesses atos de invisibilização conforme o grau de intencionalidade ou, como ele afirma, a depender de "quão ativo é o sujeito que percebe no ato de nãopercepção" (idem, ibidem). Por exemplo, se o ato de desatenção foi simplesmente um lapso de esquecimento ou se a pessoa invisibilizada é ativamente constituída como socialmente insignificante. Aqui, o argumento de Honneth é que a invisibilidade não pode ser atribuída a uma incapacidade de conhecer [cognize] o outro, mas ela decorre de fatores que são moldados socialmente; em outras palavras, o outro está presente no campo de percepção daquele que conhece, mas ele ou ela é deliberadamente desvisto ou ignorado (idem, ibidem).

$O$ ato de reconhecer o outro em um sentido social requer, portanto, que a visibilidade do outro seja admitida por meio de gestos expressivos que confirmem que aquele que percebe é afetado por ou está atento àquele que é percebido. Por exemplo, expressões como um aceno ou um sorriso, ou se afastar para permitir que alguém passe em uma rua cheia de gente. A diferença entre conhecer e reconhecer o outro na percepção, então, pode ser distinguida por meio de gestos expressivos que indicam uma afirmação positiva de sua existência social; nesse sentido, Honneth estabelece uma conexão direta entre formas de expressão, assim como de percepção, de reconhecimento. Para Honneth, esses gestos de reconhecimento são uma expressão do valor do outro, motivo pelo qual ele afirma que o reconhecimento não é secundário, mas que pode ser descrito como conferindo "expressão diretamente a uma percepção" (idem, p. 124). No que se refere às formas iniciais de percepção expressiva entre cuidador e criança, observadas na pesquisa sobre a infância, Honneth sugere que a percepção valorativa não é a mesma que a forma de "identificação individualizada" que convencionalmente formou a base para o paradigma da percepção. Nesse contexto, Honneth argumenta que o paradigma da percepção, entendido como mera identificação cognitiva, perde de vista o ato geneticamente anterior da percepção que reconhece, isto é, essa percepção não é apenas uma captura desinteressada do campo visual, mas trata-se de uma percepção que já é valorativa, que indica que o "valor das pessoas é dado 'diretamente'” (idem, pp. 125-6; Jardine, 2015, p. 56789).

Desse modo, para Honneth, o campo perceptivo já é um campo moralmente inflexionado, no sentido de que a percepção reconhece o "atributo 'digna de valor' das pessoas"; em outras palavras, já é valorativa e não apenas uma forma desinteressada de identificação cognitiva. O campo sensível já é determinado pelo valor moral das pessoas e grupos em que a percepção ocorre. A falta dessa afirmação expressiva indica então "uma deformação da capacidade humana de percepção com a qual o reconhecimento está conectado", e a invisibilização assinala um fracasso no ato de percepção no momento em que a reconhecibilidade acontece (Honneth, 2001, p. 126. Trad. nossa). 
A noção de reconhecimento afetivo e o trabalho de Honneth sobre reificação são cruciais para entendermos seu argumento sobre invisibilização. Para Honneth, as tendências de objetivação ou de reificação podem ser compreendidas como um desvio frente ao que ele se refere como um modo genuíno de se relacionar com os outros e com o mundo. Nas conferências de Reificação, Honneth desenvolve um modo existencial de reconhecimento que indica uma postura prática, e não epistêmica, perante os outros e fornece uma base para todas as outras formas normativas e institucionais de reconhecimento. A reificação nega às pessoas seu status de seres humanos e faz com que elas se tornem semelhantes a coisas e, assim, representa uma forma de patologia social e uma "anomalia de uma práxis humana" (Honneth 2018 , p. 29 [2008, p. 21]). As relações sociais reificadas mostram, portanto, que aquele que percebe se tornou um observador neutro, impassível e indiferente, com uma atitude meramente desvinculada e contemplativa em relação ao seu mundo circundante (idem, p. 35 [p. 24]). Nesse sentido, de acordo com Honneth, posturas objetivantes pressupõem "uma práxis originária, em que o ser humano adota uma relação participativa diante de si mesmo e de seu mundo circundante" (idem, pp. 40, 48, 57-58 [pp. 27, 32, 38]). Honneth descreve essa forma existencialista de reconhecimento como uma forma de atenção [attentiveness] ou engajamento com os outros, uma forma de reconhecimento afetivo que assume um compromisso prático afirmativo com os outros e com o mundo. Assim, o reconhecimento pode ser entendido como uma afecção [affectedness] em relação aos outros e, para Honneth, posturas de reconhecimento mais explicitamente normativas são construídas sobre essa forma primária de engajamento afetivo (idem, pp. 200-202 [pp. 151-2]). Embora essa forma de engajamento afetivo seja precursora de todas as outras formas de interação humana, ela não determina a postura específica adotada em relação a uma outra pessoa. A afetividade ou emoção específicas não são predeterminadas, mas a forma de engajamento e de atenção deve expressar uma forma de "afecção existencial" que expressa uma tomada de conhecimento da existência do outro (idem, ibidem).

Honneth, portanto, explica a reconhecibilidade de duas maneiras diferentes, embora relacionadas: a primeira é apresentada no ensaio "Invisibilidade", onde a reconhecibilidade é retratada como um ato de percepção no qual o valor das pessoas é dado diretamente antes da identificação cognitiva; a segunda é desenvolvida em suas conferências em Reificação, onde a forma pré-cognitiva de reconhecimento é descrita como uma forma primária de afetividade, na qual a existência do outro é reconhecida em termos afetivos ou emocionais básicos.

Esses argumentos finais assinalam uma diferença importante entre as posições de Rancière, Butler e Honneth. Enquanto Butler explica o fracasso da apreensão ou da reconhecibilidade em termos de quadros discursivos e epistemológicos que 
previamente determinam quem é reconhecível, e Rancière sugere que os fenômenos de reconhecibilidade são determinados pela ordem institucional que estabelece a partilha do sensível, Honneth sugere que as formas de invisibilização e o fracasso do reconhecimento podem ser atribuídos a relações reificadas ou patológicas. Honneth tem como ponto de partida uma posição intersubjetivista forte em que se postula uma forma originária de intersubjetividade ou de relacionalidade afetiva, e argumenta que formas de objetivação ou de reificação podem ser entendidas como patologias sociais: isto é, como perda temporária, encobrimento ou esquecimento de uma forma elementar de reconhecimento. Nesse sentido, parece que já existem expectativas proto-normativas nas formas de intersubjetividade afetiva que estão na base da concepção honnethiana de percepção e de reconhecimento afetivo; e isso, por sua vez, está na base de sua concepção de segunda ordem mais explicitamente normativa e institucional que ganha corpo em lutas sociais e históricas.

Butler, em contrapartida, evita pressupor uma postura normativa que fundamente sua concepção de reconhecibilidade e reconhecimento. Em vez disso, ela sugere que os quadros epistemológicos que estruturam as diferentes ordens sociais determinam o campo da percepção e da reconhecibilidade. Isso não quer dizer que ela não deixe nenhum espaço para a resistência. Pelo contrário, como vimos anteriormente, ela sugere que, para que a exclusão de certas vidas e a invisibilização persistam, é preciso que esses quadros sejam reiterados e renovados; todavia, permanece incerto qual é a base normativa para rompermos com o campo epistemológico e perceptivo. Como resultado, ficamos com a seguinte questão: se nossa capacidade de perceber a precariedade ou até mesmo de apreender o outro é estruturada por quadros normativos de inteligibilidade que estabelecem os domínios do conhecível, sobre quais fundamentos podemos basear nosso julgamento e reflexividade sobre o outro vulnerável? Em outras palavras, se o que podemos saber ou perceber está sempre enquadrado por regimes de normalização, sobre quais bases podemos perceber outra vida como uma vida? Embora em Quadros de guerra Butler explique que, para persistirem, os regimes normativos têm de ser reiterados, é possível sugerir que essa afirmação não responde plenamente à questão sobre os fundamentos a partir dos quais podemos julgar o que são formas de vida melhores ou piores, ou formas de vulnerabilidade melhores e piores.

Em contraposição, embora a concepção de Rancière sobre a partilha do sensível pareça sugerir, à primeira vista, um tratamento sistêmico e totalizante da ordem institucional, ela é, em última análise, mais agonística e menos ancorada no tipo de estruturas epistemológicas e simbólicas assumidas pela concepção pósestruturalista de Butler. Nesse sentido, como veremos adiante, em seus trabalhos mais recentes, Rancière salienta os aspectos corporificados e sensíveis de formas de experiência estética alternativas e as maneiras pelas quais estas podem perturbar 
a ordem institucional e, assim, "alterar a cartografia do perceptível, do pensável, do factível” (Rancière, 2016, p. 147. Trad. nossa). Além disso, a teoria de Rancière está ancorada em uma noção a priori de igualdade que, em larga medida, fornece o mesmo tipo de base normativa que a noção de reconhecimento a priori de Honneth. Embora Rancière negue que seu argumento da igualdade absoluta seja normativo, é muito difícil negar o papel normativo dessa noção na orientação de experiências estéticas e políticas (Deranty, 2016, pp. 33-80; p. 65). É para esse conjunto de questões que nos voltaremos agora.

\section{Invisibilização e Distribuição do Sensível: Rancière sobre a Reconhecibilidade}

Em sua discussão sobre a política em $O$ desentendimento, Rancière efetivamente fala sobre o problema da reconhecibilidade (ou da falta de reconhecimento) quando descreve a política como um meio pelo qual a "ordem natural de dominação é interrompida pela instituição de uma parcela dos sem-parcela" (Rancière, 1996, p. 26 [1999, p. 11]). Assim, para Rancière, a política não apenas "ativa a igualdade como princípio", mas torna visíveis aqueles que não têm parcela de nada, seja "os pobres dos tempos antigos, o terceiro estado ou os proletários modernos" que agem em nome de um mal que lhes é feito, que não têm voz e permanecem invisíveis (idem, p. 24 [p. 9]). Como Rancière explica, presume-se que a parcela dos sem-parcela não fala "porque são seres sem nome, privados de logos". Não há discurso considerado possível para os seres sem nome cuja existência não é reconhecida [recognized] (idem, p. 36 [pp. 23-24]).

Como descreve Rancière: “A política é primeiramente o conflito em torno da existência de uma cena comum, em torno da existência e da qualidade daqueles que estão ali presentes” (idem, p. 39-40 [pp. 26-27]). Desse modo, a preocupação de Rancière é sublinhar como, na ordem política, o palco se baseia em uma exclusão que invisibiliza certos grupos e indivíduos e que lhes nega a própria existência. Com o termo polícia, ele se refere a essa organização particular da ordem política, caracterizada por uma distribuição e divisão fundamental de papéis e lugares. A polícia, assim, é entendida no sentido mais amplo do termo (também empregado por Foucault), como abarcando "a governança mais geral da ordem social”, não apenas a força policial ou o policiamento. Em comparação com Foucault, no entanto, Rancière deixa claro que policiar não se reporta à “disciplinarização dos corpos (...) [mas] a uma configuração de ocupações e às propriedades dos espaços em que essas ocupações estão distribuídas" (idem, p. 42 [pp. 28-29]). Assim, o sistema ou a ordem política legitimam não apenas divisões fundamentais, mas também a distribuição de lugares, de ocupações e de papéis e "situa os corpos em seu lugar" (idem, p. 40 [p.27]). 
Em $O$ desentendimento, apesar da ênfase no logos ou discurso, no dizível e no indizível, Rancière já aponta dimensões mais sensoriais e corporificadas. Como ele afirma:

A polícia é, antes de mais nada, uma ordem dos corpos que define as divisões entre os modos do fazer, os modos de ser e os modos do dizer, que faz com que tais corpos sejam designados por seu nome para tal lugar e tal tarefa; é uma ordem do visível e do dizível que faz com que uma atividade seja visível e outra não o seja, que uma fala seja entendida como discurso e outra como ruído (idem, p. 42 [p. 29], trad. mod.).

Nessa passagem central, Rancière coloca o problema da reconhecibilidade e da visibilidade no centro de suas preocupações. A identificação da visibilidade e da invisibilidade, do discurso que não é ouvido, ou que é simplesmente designado como um ruído incoerente, é precisamente outro modo de falar sobre o problema dual do reconhecimento e do que constitui a reconhecibilidade. Para Rancière, assim, a reconhecibilidade corresponde à visibilização no interior dos campos do sensível e do político.

Ademais, Rancière compreende esse modo de distribuição nos termos da forma sensível e da forma "estética”. Com isso, a ordem política é conceitualizada nos termos do que Rancière se refere como a partage du sensible, a partilha do sensível. Essa formulação chama atenção para a maneira pela qual formas sensíveis e visíveis específicas são definidas, e explicita como o campo sensível é determinado por modos dominantes de compreensão que moldam a percepção. Este foco no visível e no invisível é um aspecto compartilhado por Rancière, Honneth e Butler. Honneth, em seu diálogo com Rancière, admitiu explicitamente esse interesse comum nos "mecanismos que transformam as pessoas em seres socialmente invisíveis"; e, em certos momentos, algumas formulações de Rancière a respeito da ordem do sensível $e$ do dizível encontram ressonância com certas visões de Butler, particularmente quando ela procura categorizar os mecanismos que estabelecem quem ou o que é apreensível, inteligível e reconhecível (Honneth, 2016).

Em seu trabalho mais recente, Rancière articula de maneira mais acabada a conexão entre política, estética e a partilha do sensível. Em A partilha do sensível: estética e política, por exemplo, ele descreve a partilha do sensível como "o sistema de evidências sensíveis que revela ao mesmo tempo a existência de um comum" ou que delimita o que é percebido e o modo como diferentes parcelas e posições são definidas (Rancière, 2005, p. 15 [2004, p. 7]). A estruturação das diferentes parcelas e posições é baseada em formas de atividades e de ocupações que tanto determinam sua partilha como designam quem tem "parcela na comunidade de cidadãos” (idem, ibidem). Nesse contexto, Rancière é bastante claro: a estética não deve ser compreendida no sentido mais convencional, como mera teoria da arte, nem simplesmente como "uma teoria da sensibilidade, do gosto e do prazer" 
para o espectador desinteressado ou para o amante das artes (idem, p.13 [p. 4]). Em lugar disso, estética diz respeito a "um regime específico de identificação e reflexão das artes: um modo de articulação entre maneiras de fazer, as formas de visibilidade dessas maneiras de fazer e modos de pensabilidade de suas relações” (idem, ibidem). Como esclarece Rancière, a estética pode ser compreendida "como o sistema das formas a priori que determina o que se dá a sentir" (idem, p.16 [p.8], trad. mod.). Além disso, em uma passagem que traz à tona uma constelação de preocupações a respeito da reconhecibilidade e da invisibilidade, Rancière define a inter-relação entre política e estética como "um recorte dos tempos e dos espaços, do visível e do invisível, da palavra e do ruído que define ao mesmo tempo o lugar e o que está em jogo na política como forma de experiência. A política se ocupa do que se vê e do que se pode dizer sobre o que é visto, de quem tem competência para ver e qualidade para dizer, das propriedades do espaço e dos possíveis do tempo" (idem, p. $16-17$ [p.8]).

Uma revolução ou intervenção estética sinalizaria uma significativa “transformação nas formas de experiência” (Rancière, 2016b, p.78. Trad. nossa) e perturbaria ou interviria "na distribuição geral das maneiras de fazer e nas relações que mantêm com modos de ser e com formas de visibilidade" (Rancière, 2005, p. 16 [2004, p. 8]). Aquilo a que Rancière se refere como experiências ou práticas estéticas aponta para uma repartilha do sensível ou uma "reconfiguração do espaço político" (Rancière, 2016b; Cf. Genel, 2016). Em seu trabalho mais recente, ele está interessado no caráter perturbador da experiência estética e em como essa experiência rompe com percepções pré-concebidas acerca do "modo pelo qual os corpos se ajustam às suas funções e finalidades" e, com isso, desafia o consenso que mantém a partilha do sensível (Rancière, 2016a, p. 145. Trad. nossa). Como explica Rancière, porém, essa intervenção estética não deve ser compreendida como se estivesse confinada à esfera da arte, tampouco a estética deveria ser concebida como uma esfera autônoma que surgiu com a modernidade. Trata-se, antes, de "uma revolução na partilha de formas e capacidades de experiência que podem ser compartilhadas por este ou aquele grupo social" (idem, p. 147). Essas experiências estéticas são políticas pois rompem o campo sedimentado do sensível e desafiam as práticas e os modos do que é dizível, factível e visível, que são tomados como dados.

Rancière se refere a esses atos políticos como uma forma de subjetivação, que diz respeito, em seus termos, a algo como o fazer do sujeito por meio do tornar-se um ator político, distinto da parcela ou dos papéis que a ordem social havia lhe designado. A política-estética é descrita, nesse sentido, como algo que possibilita uma forma de des-identificação da ordem institucional dominante, que procura delimitar os sujeitos. Modos de des-identificação e ação política-estética possibilitam, portanto, que formas emancipadas de subjetividade sejam moldadas. Assim, no esquema de 
Rancière, os indivíduos são subjetivados apenas por meio dessas práticas disruptivas. É importante observar que o emprego dado por Rancière ao termo subjetivação é claramente distinto daquele encontrado no trabalho de Butler, que o extrai de um modelo althusseriano, como discutimos anteriormente. É significativo que tanto Rancière como Butler compartilham um pano de fundo althusseriano; no caso de Rancière, isso ocorre diretamente, uma vez que ele foi aluno de Althusser, no caso de Butler, isso aparece no uso explícito das formulações althusserianas em seu trabalho, especificamente em $A$ vida psíquica do poder. Todavia, no trabalho de Butler, subjetivação conserva um significado quase oposto daquele atribuído por Rancière; para ela, a subjetivação concerne ao modo pelo qual o sujeito é em larga medida estruturado e determinado pela linguagem e pelas estruturas simbólicas.

Apesar das diferentes concepções de subjetivação, Rancière e Butler se aproximam no que diz respeito às concepções de inteligibilidade e reconhecibilidade. Não obstante, ainda que Rancière entenda o sistema como algo cindido por uma divisão essencial que torna certas parcelas invisíveis, sua concepção de política baseia-se em uma reivindicação a priori de igualdade e, além disso, ele indica que as formas sensíveis podem ser tornadas visíveis por meio de intervenções estéticas que reconfigurem a ordem política. Deste modo, sua concepção é mais agonística no sentido de que a parcela dos sem-parcela pode romper a partage du sensible, em alguns casos simplesmente ao provocar uma ruptura no tecido do sensível. Entretanto, enquanto Rancière se afastou radicalmente de Althusser, Butler, em alguns aspectos, continua limitada por sua herança althusseriana e estruturalista, que se infiltra em sua posterior concepção de invisibilização e reconhecibilidade nos termos dos quadros de inteligibilidade.

Em trabalhos mais recentes, Rancière passa a desenvolver uma concepção de estética que é enriquecida com cenas que reforçam os elementos afetivos, sensíveis e corporificados, e sua representação de práticas e estéticas e políticas pinta uma imagem dinâmica do campo sensível. Como Rancière escreve em 0 espectador emancipado: "O que o artista faz é costurar um novo tecido do sensível, arrancando perceptos e afectos das percepções e afecções que constituem o tecido da experiência ordinária” (2011, p. 56. Trad. nossa). As práticas estéticas alteram os campos sensível e visual em que a percepção e a experiência se desdobram; nesse sentido, essas práticas são atos políticos pois possibilitam "novos modos de construção política de objetos comuns" (idem, ibidem). Em momentos como esse, as descrições que Rancière faz da prática estética lembram os escritos de Merleau-Ponty a respeito da pintura cubista, que oferece, segundo ele, um meio para a reconstituição do campo fenomênico e rompe com a natureza pressuposta dos modos dominantes de percepção, que é tomada como dada. Como sugere Rancière, a experiência estética está associada a “novos modos de percepção, de perceptibilidade das coisas (...) que 
podem (...) promover diferentes formas de vida” (2016b, p. 78). Além disso, em alguns momentos, Rancière adota modos de explicação mais fenomenológicos e existenciais a respeito do campo do sensível e do tecido intersubjetivo da comunidade. Como afirma ele, de modo evocativo: "Os seres humanos estão atrelados por um certo tecido sensorial, uma certa distribuição do sensível, que define seu modo de ser em conjunto; e a política diz respeito à transformação do tecido sensorial do 'ser em conjunto"” (2011, p. 56).

Em suaúltima formulação sobre uma forma sensata de ser em conjunto, Rancière define "um coletivo humano" como "um entrelaçamento e entrançamento conjunto de sensações do mesmo jeito" (idem, ibidem). Em alguns aspectos, esse modo de ser em conjunto pode ser visto como a versão de Rancière para a intersubjetividade existencial e afetiva de Honneth. Rancière, porém, defende sua concepção sobre a transformação do tecido sensível recorrendo a uma noção originária de igualdade. Ele sugere que: "costurar esse novo tecido significa criar uma forma de expressão comum ou uma forma de expressão da comunidade - a saber, 'a canção da terra e o lamento da humanidade'”. Embora, por vezes, a compreensão de Rancière sobre uma noção originária de igualdade pareça assumir um tom normativo, ele afirma que se trata apenas de um método para a política que é baseado em uma condição estrutural a priori (Rancière 2016a; Deranty 2016, pp. 65-6).

Esse recurso à igualdade é uma característica que distingue Honneth e Rancière, uma vez que Honneth decididamente baseia sua teoria em uma noção de liberdade e nas normas de reconhecimento mútuo. Para Honneth, as normas de reconhecimento têm de ser constituídas imanentemente e são construídas por meio de lutas sociais e históricas. Nesse sentido, toda a concepção de Honneth se baseia em relações entre sujeitos dentro do campo do social; ele não aceita uma visão que ressalta forças externas ou sistematizadoras que, de alguma forma, se separam e se destacam do campo da ação social. Mesmo que Honneth e Rancière discordem quanto ao valor primário que dá base a suas teorias. Ainda que algumas de suas formulações, tais como a noção de ordem policial e de parcela dos sem-parcela indiquem, em alguns momentos, tendências sistematizadoras (Rancière 2016a, p. 136), Rancière também compreende a ordem institucional como constituída de modo imanente e deixa claro que não se trata de uma estrutura ideológica, e sim do resultado de formas de consensos e dissensos. Em contrapartida, o recurso de Butler aos quadros de inteligibilidade, que estruturam e constituem a ordem institucional e a política, não é uma construção imanente moldada pelos sujeitos aos quais ela é imposta. Com isso, pode-se argumentar que, ao desenvolver posteriormente a experiência estética e os modos de intervenção por meio dos quais a ordem política poderia ser reconfigurada, Rancière oferece uma descrição mais rica do campo do sensível do que aquela proposta por Butler. Sua concepção singular acerca da inter-relação entre 
estética e política abre um espaço de possibilidades para repensarmos o problema da invisibilidade, da reconhecibilidade e do campo da percepção, o que, em alguns aspectos, complementa a concepção normativa e intersubjetiva de Honneth, embora também haja diferenças importantes.

\section{Reconfigurando a reconhecibilidade}

Como discutido anteriormente, Butler, Honneth e Rancière contribuem para a questão sobre como o problema da reconhecibilidade pode ser reconfigurado. Butler, em especial, oferece uma concepção interessante que identifica de modo frutífero um conjunto de distinções entre reconhecibilidade e reconhecimento, e que explica, até certo ponto, por que indivíduos e grupos não são apreendidos no interior do campo de percepção antes de interações que envolvem formas normativas de reconhecimento. Sua concepção é importante pois salienta como a reconhecibilidade fornece as condições que tornam o reconhecimento possível e indica a prioridade da reconhecibilidade diante do reconhecimento. Apesar de Butler identificar essa constelação de problemas, sua conceitualização do campo que estrutura a reconhecibilidade nos termos de quadros do conhecível é marcada por uma orientação demasiadamente discursiva e epistemológica e carece de uma explicação convincente acerca das normas ou valores que são subjacentes a essa concepção.

Rancière, por outro lado, oferece uma concepção mais abrangente do campo sensível e perceptivo que também ressalta aspectos intersubjetivos e corporificados, e, além disso, mostra como esse campo pode ser rompido ou modificado por meio de intervenções estéticas que reconfiguram a ordem política. A concepção mais agonística, na qual o tecido do sensível é rompido, pode ser vista como a versão de Rancière de uma luta por reconhecibilidade. No entanto, um dos problemas mais significativos da concepção de Rancière é o de que ela não oferece uma base explicitamente normativa para sua crítica e apenas postula uma noção a priori de igualdade, o que o deixa suscetível a uma crítica semelhante àquelas dirigidas a Butler. Sobre quais fundamentos Rancière justifica a base normativa de sua crítica? Qual a justificativa para afirmar que a igualdade é um mero fato estrutural? Nesse sentido, a força da teoria honnethiana do reconhecimento é a de fornecer essa concepção normativa e enfatizar como as normas de reconhecimento devem ser constituídas de modo imanente, e não meramente asseveradas. No que tange à questão da reconhecibilidade, Honneth também oferece uma descrição mais convincente de como a percepção do outro já é um ato valorativo, no qual o valor dos outros é diretamente dado, e não se trata apenas de uma apreensão meramente desinteressada do campo visual. Rancière não oferece uma concepção equivalente 
da complexidade da inter-relação entre reconhecibilidade e percepção ou do que ocorre no momento da percepção. Não obstante, o argumento aqui é que Rancière oferece uma concepção mais rica do campo sensível e do perceptivo e de como a partilha do sensível pode ser reconfigurada por meio do que ele chama de experiência estética.

Embora o problema da reconhecibilidade seja enfrentado apenas rapidamente na concepção de dois níveis desenvolvida por Honneth, ele identifica um nível prélinguístico e pré-cognitivo da afeição existencial que é precursora do reconhecimento. Nesse sentido, para Honneth, o campo do sensível é aquele em que somos primeiro afetados pelo outro em um nível pré-reflexivo, e nossa tomada de conhecimento da existência do outro se expressa por formas corporificadas e gestuais de comunicação. Além disso, é possível defender que, dentre os três pensadores, Honneth é aquele que oferece a concepção mais robusta das relações intersubjetivas, sobre as quais normas de reconhecimento são articuladas, e uma noção de reconhecibilidade que é baseada em uma forma primária de afeição e atenção ao outro na percepção. ${ }^{9}$ Nesse sentido, a sugestão de Honneth é a de que é possível estabelecer uma ligação direta entre percepção, afetividade e reconhecibilidade. Ele mostra, portanto, como juízos de níveis mais altos estão ancorados em níveis mais baixos de engajamento atento e afetivo. Como consequência, em vez de considerar que a identificação cognitiva do indivíduo tenha uma prioridade genética no ato da percepção, Honneth argumenta que o reconhecimento afetivo é anterior à cognição e que forma a base de nossa percepção dos outros. Nesse sentido, como vimos anteriormente, Honneth afirma que a reificação indica um esquecimento do reconhecimento, ou seja, indica que uma forma contemplativa e desvinculada de cognição perturbou a base afetiva e as formas de percepção não-reificantes. Para Honneth, entretanto, essa afirmação está ligada a uma tese normativa e intersubjetiva. 0 esquecimento do reconhecimento significa que podemos identificar uma forma pura e não-reificada de intersubjetividade e retornar àquilo a que Honneth se refere como o estado primordial de reconhecimento afetivo.

Honneth supõe, portanto, que a identificação e a crítica de certas formas de percepção como objetivantes e reificantes dependem de uma forma de reflexividade de nível mais elevado. As implicações dessa consideração são as de que precisamos de uma determinada consciência reflexiva e normativa para identificarmos os casos em que a afetividade e a atenção fracassaram, e nos quais não ocorre uma virada ativa que indique reconhecibilidade, como ilustra o exemplo de Morrison com o qual começamos. As implicações da concepção de Honneth, ou o ímpeto crítico por trás dela, sugerem que hábitos de percepção reificantes e invisibilizadores também

9 Para meu trabalho sobre Husserl e Honneth a respeito de uma noção de afetividade e atenção na percepção, ver "Habit, Attention and Affection: Husserlian Inflections" (no prelo). 
podem ser modificados e rompidos, e, desse modo, redirecionados para que possam retomar seu fluxo afetivo (Petherbridge, 2017).

$\mathrm{Na}$ teoria de Honneth, a capacidade de modificar ou transformar formas reificantes de percepção, mesmo em um nível afetivo, é formulada em sua concepção de dois níveis do reconhecimento, de acordo com a qual formas afetivas de engajamento formam a base de um nível primário sobre o qual é construído um segundo nível de reconhecimento explicitamente normativo. Para este fim, a abordagem de Honneth confia na influência crítica e normativa dos conflitos históricosociais por reconhecimento, que continuam alimentando demandas normativas e modificações nos níveis da percepção referentes à afetividade e à atenção. Desse modo, o ímpeto pela modificação da percepção dos outros e a capacidade de redirecionar a afetividade assume um tipo de prática reflexiva que desperta uma consciência sobre as formas habituais de percepção e motiva a interrupção e a modificação dos hábitos perceptivos. Quanto à modificação dos hábitos de percepção que impedem a reconhecibilidade, precisamos primeiro ter consciência deles, para então nos motivarmos a adotar novos hábitos de percepção que expressem uma valoração positiva do outro na consciência perceptiva básica que temos dele ou dela. Por outro lado, quando essa tomada de conhecimento não ocorre, como em formas racializantes de percepção, isso pode motivar o sujeito que tem sido ignorado ou que não é visto a buscar ativamente algum tipo de atenção ou responsividade do outro. O importante, então, é que há um processo de reforço mútuo entre os níveis mais altos de reflexibilidade, cognição e julgamento, e os hábitos de afeto e atenção na percepção básica ou os processos de reconhecibilidade. Embora perspicaz, o trabalho de Honneth oferece apenas uma consideração preliminar sobre a diferença entre reconhecibilidade e reconhecimento, que mostra como formas iniciais de percepção formam um ato valorativo, e, desse modo, aponta a importância das formas primárias de reconhecibilidade na percepção. Embora Honneth ofereça uma concepção de formas pré-reflexivas de reconhecibilidade, ele não oferece uma concepção abrangente do tecido do campo sensivel ou perceptivo de forma mais geral. ${ }^{10}$ Quando colocada junto de uma concepção mais rica do campo sensível, como aquela proposta por Rancière, temos uma indicação de como a partilha do sensível pode ser transformada de forma mais geral. Nesse aspecto, estabelecer um diálogo entre esses pensadores aponta para como o problema da reconhecibilidade pode ser reconfigurado. ${ }^{11}$

10 Por outro lado, ensaios sobre invisibilidade e afetividade representam uma parte do projeto de Honneth que não foi desenvolvida e, em muitos aspectos, ele abandonou os elementos mais corporificados e pré-discursivos da experiência que outrora caracterizaram de modo mais marcado sua abordagem. Cf. também a leitura de Deranty (2016).

11 Para uma discussão mais detalhada que amplia para além destas posições, ver minha descrição em formato de livro: When is One Recognizable? (no prelo). 


\section{Referências}

Butler, J. (2015). Quadros de Guerra: quando a vida é passível de luto? $1^{\text {a }}$ edição. Rio de Janeiro: Civilização Brasileira [Frames of War: When is Life Grievable? New York: Verso, 2010].

Butler, J. (2019a). Corpos em aliança e a política das ruas: notas para uma teoria performativa de assembleia. $3^{a}$ edição. Rio de Janeiro: Civilização Brasileira [Notes Toward a Performative Theory of Assembly. Cambridge, MA., and London: Harvard University Press, 2015].

Butler, J. (2019b) Vida Precária: os poderes do luto e da violência. $1^{a}$ edição. Belo Horizonte: Autêntica Editora [Butler, J. (2004). Precarious Life: The Powers of Mourning and Violence. London \& New York: Verso, 2004].

Deranty, J-P. (2016). "Between Honneth and Rancière: Problems and Potentials of a Contemporary Critical Theory of Society". In: Recognition or Disagreement: A Critical Encounter on the Politics of Freedom, Equality and Identity. Genel, K. and Deranty, J-P. (eds.). New York: Columbia University Press.

Ellisone, R. (2020). O homem invisível. Rio de Janeiro: José Olympio Ltda [Invisible Man. New York: Random House, 1995]

Ferrarese, E. (2011). Judith Butler's 'not particularly postmodern insight' of recognition. Philosophy \& Social Criticism, 37(7), 759-773. DOI: https://doi.org/10.1177\%2F0191453711410029

Honneth, A. (1995). "Moral Consciousness and Class Domination: Some Problems in the Analysis of Hidden Morality". In The Fragmented World of the Social: Essays in Social and Political Philosophy. Wright, C.W. (ed.). Albany: SUNY Press [originalmente publicado em Praxis International, 2; Abril 1982].

Honneth, A. (2001). Invisibility: On the Epistemology of 'Recognition'. Recognition, Axel Honneth \& Avishai Margalit, Supplement of the Aristotelian Society, 75, 127-139.

Honneth, A. (2015). O Direito da Liberdade. Tradução de Saulo Krieger. São Paulo: Martins Fontes [Freedom's Right: The Social Foundations of Democratic Right. New York: Columbia University Press, 2015]

Honneth, A. (2016). “Recognition or Disagreement”. In: Recognition or disagreement: a critical encounter on the politics of freedom, equality, and identity. Honneth, A.; Rancière, J.; Genel, K. \& Deranty, J-P. (pp. 33-80). New York: Columbia University Press.

Honneth, A. (2018b). Reificação: um estudo de teoria do reconhecimento. Trad. Rúrion Soares Melo. São Paulo: Editora Unesp [Reification: A New Look at an Old Idea. Jay, M. (ed.). Oxford; New York: Oxford University Press, 2008]

Jardine, J. (2005). Stein and Honneth on Empathy and Emotional Recognition. Human Studies, 38(4), 567-589. DOI: https://doi.org/10.1007/s10746-015-9361-5

Mills, C. (2007). Normative Violence, Vulnerability, and Responsibility. differences, 18(2), 133-156. DOI: https://doi.org/10.1215/10407391-2007-005

Morrisson, T. (2019). O olho mais azul. $2^{a}$ edição. São Paulo: Companhia das Letras [The Bluest Eye. New York: Vintage Books, 2007]. 
Petherbridge, D. (2013). The Critical Theory of Axel Honneth. Lanham \& New York: Lexington Books.

Petherbridge, D. (2017). Racializing Perception and the Phenomenology of Invisibility, Body/Self/Other: The Phenomenology of Social Encounters. Dolezal, D. \& Petherbridge, D. (eds.). New York: SUNY Press.

Petherbridge, D. (2018). "How Do We Respond? Embodied Vulnerability and Ethical Responsiveness". In: New Feminist Perspectives on Embodiment. Fischer, C. and Dolezal, L. (eds.). London: Palgrave MacMillan.

Petherbridge, D. Habit, Attention and Affection: Husserlian Inflections (no prelo).

Petherbridge, D. When is One Recognizable? (no prelo).

Rancière, J. (1996). O Desentimento. São Paulo: Editora 34 [Disagreement: politics and philosophy. Minneapolis: University of Minnesota, 1999].

Rancière, J. (2005) A partilha do sensível: estética e política. São Paulo: Editora 34 [The Politics of Aesthetics: The Distribution of the Sensible. Editado e traduzido por Gabriel Rockhill. London: Bloomsbury Academic, 2004].

Rancière, J. (2011). The Emancipated Spectator. Tradução de Gregory Elliott. London \& New York: Verso.

Rancière, J. (2016a). "The Method of Equality: Politics and Poetics". In: Recognition or Disagreement: A Critical Encounter on the Politics of Freedom, Equality and Identity. Genel, K. and Deranty, J-P. (eds.). New York: Columbia University Press, pp. 133-155.

Rancière, J. (2016b). The Method of Equality: Interviews with Laurent Jeanpierre and Dork Zabunyan. Tradução de Julie Rose. Cambridge: Polity Press.

Varga, S. (2010). Critical Theory and the Two-Level Account of Recognition - Towards a New Foundation? In Critical Horizons, 11(1), 19-33. DOI: http://doi.org/10.1558/crit.v11i1.19 